\title{
Micro Scale Environmental Characteristic and Fear of Crime
}

\author{
Eylem Akman Cinar, Ebru Cubukcu \\ Dokuz Eylul University, Izmir, Turkey \\ ebru.cubukcu@deu.edu.tr
}

\begin{abstract}
This study investigated the relation between crime, fear, and micro level physical environmental features: physical incivilities, places that afford concealment (or refuge), limited prospect, and blocked escape. Low and high crime streets in Istanbul, Turkey was determined. Then 68 streets were selected via cluster random sampling and evaluated by two investigators at the site and by 127 people via photographs for perceived safety, upkeep (as an indicator of physical incivilities) the extent to which they afford wide vista (prospect) and easy escape and concealment opportunities, the density and height of trees, shrubs, and walls. Results supported the theory and the findings of previous empirical studies.
\end{abstract}

Keywords: Crime, Perception of safety, Fear, Prospect-refuge theory, Concealment, Incivilities

eISSN 2514-751X @ ( 2018. The Authors. Published for AMER ABRA cE-Bs by e-International Publishing House, Ltd., UK. This is an open access article under the CC BY-NC-ND license (http://creativecommons.org/licenses/bync-nd/4.0/). Peer-review under responsibility of AMER (Association of Malaysian Environment-Behaviour Researchers), ABRA (Association of Behavioural Researchers on Asians) and cE-Bs (Centre for EnvironmentBehaviour Studies), Faculty of Architecture, Planning \& Surveying, Universiti Teknologi MARA, Malaysia.

DOI: https://doi.org/10.21834/aje-bs.v3i7.265 


\subsection{Introduction}

In his seminal paper, titled as 'A Theory of Human Motivation' Maslow (1943) argued that safety overshadows the other basic human needs (such as 'love and belonging', 'self esteem', and 'self actualization'). Given that, the topic of crime in general and perception of safety in particular has long attracted researchers from different fields, such as criminology, architecture, planning and environmental psychology. This study aims to focus on the concepts of crime and perception of security (hereafter referred to as fear) from environmental psychologists' perspective.

Crime and fear has been considered as a main problem threatening quality of life, because it limits people's activities and worsens health (Nasar \& Jones, 1997; Nasar \& Fisher 1993; Newman, 1972). General knowledge and empirical evidence showed that reductions in fear (and actual crime) could be achieved through environmental design. As crime tends to concentrate in some environments and some environments evoke higher levels of fear than others (Nasar \& Jones, 1997; Nasar \& Fisher 1993), a number of studies have been devoted to the distribution of crime and fear over space, and the social, economical and physical environmental variables affecting crime and fear. For environmental psychologists, physical environmental variables are more important as they can be controlled through the design and planning processes. Although researchers may investigate physical environmental features at two levels (macro and micro levels), environmental psychologist tend to focus on the micro level characteristics (Nasar \& Fisher, 1993) as they can be controlled to the means of urban design. Thus, this study aims to investigate the relation between crime, fear, and micro level physical environmental features.

In theory, physical incivilities, places that afford concealment (or refuge), limited prospect, and blocked escape contribute both to crime and fear (Nasar, Fisher \& Grannis, 1993). Physical incivilities (such as litter and low quality buildings) in an environment convey messages about the social and physical conditions of an area and contribute to fear but not to actual crime (Nasar \& Fisher 1993). According to Appleton's (1975) prospect-refuge theory people prefer places offering large fields of view (prospect) and protection from threat (refuge). However, from the perspective of potential victims and offenders preferences for prospect and refuge may differ. For example, open vistas (prospect) may represent a positive affordance (for a potential victim) or a negative one (for a potential offender) (Nasar \& Fisher, 1993; Nasar \& Jones, 1997). Similarly, potential victims may avoid places of concealment (refuge) as such places may convey messages about the presence of potential offenders who may surprise them. Grounded on Appleton's prospect-refuge theory, Nasar and Fisher (1993) argued that fear is not only determined by the extent to which an environment provides a wide vista, places for concealment, but also by the extent to which it provides an opportunity to escape (closure). Both potential victims and offenders may favor places that afford easy escape. Research showed that these three variables (prospect, refuge and closure) may be dependent to each other. For example, areas of blocked prospect tended to have concealment. Similarly, a place that affords concealment (such as a wall) may limit the opportunity to escape. Also, researchers tend to mention trees, shrubs, walls as the most important physical features that determine 
whether an environment affords concealment, limited prospect and blocked escape. In brief, this study aims to focus on the extent to which an environment involves physical incivilities, limited prospect, high refuge and blocked escape.

Previous empirical studies used a variety of measures (responses to site plan, response on-site, descriptions of behavior, and observations of spatial behavior) to study the relation between crime, fear, and physical environmental characteristics and confirmed the theoretical approach that people avoid certain areas because of high concealment potential for offenders and blocked prospect and escape for potential victims. Similarly, research have provided evidence that areas characterized by limited prospect, blocked escape and high concealment evoke fear (Fisher \& Nasar, 1992; Nasar \& Jones, 1997; Fisher \& Nasar, 1995; Nasar \& Fisher, 1993) and those physical environmental characteristics are associated with higher levels of crime (Nasar \& Fisher, 1993; Stoks, 1983). All these studies were conducted in developed countries. However, the influence of those physical environmental features on crime and fear could vary with the site. Thus, this study aims to test this theoretical approach in a metropolitan city of a developing country to see whether the findings of previous studies could be generalized to such cultures.

\subsection{Methodology}

\section{Site}

Crime and fear is a major problem in metropolitan cities and Istanbul, Turkey, is not an exception. The coastal strip of the Bosphorus, Istanbul, Turkey was selected to analyze the spatial distribution of crime and fear in Istanbul for two reasons. First, the area is large enough to show variations on physical environmental features. Second, it is difficult to access data on crime in developing countries (Ergun \& Yirmibesoglu, 2007) and data collected by Istanbul Metropolitan Area was available.

The area is about 4632 hectare, involves 49 neighborhoods within the districts of Besiktas, Sariyer, Beykoz and Uskudar, and extends from Ortakoy to Rumelikavagi at the European side and from Hacihesna Hatun to Anadolukavagi at the Anatolian side. For the selected area, the crime data obtained from the Istanbul Police Department (which was classified according to type, date, and the location where the crime had been committed) involved more than 60 types of crimes committed in 2007. The crime types which were reclassified as personal crimes (murder, injury and / or harm) were eliminated from the data set as their root causes of such crime types are not environmental affordances. The location of property crimes (robbery from cars, businesses and homes, armed robbery, pick pocketing, snatch thievery) was mapped at street level. The number of crimes per street vary from 0 to 27.75 streets were selected by cluster random sampling to represent 'no crime streets' ( 25 streets on which number of crimes $=0$ ), 'low crime streets' ( 25 streets on which number of crimes $<3$ ) and 'high crime streets' ( 25 streets on which $4<$ number of crimes < 27). 


\section{Procedure}

The selected 75 streets were visited by two investigators (one whom was the first author of this article) and photographed at three locations (at the start, end, and middle of the street) and two directions (Figure 1). 5 streets were eliminated from the data set during site visits, because the street names were duplicated or the streets extend beyond the coastal strip of the Bosphorus area. 2 streets were eliminated because of the inappropriate photograph quality. Thus, the analyses focused on 68 streets.

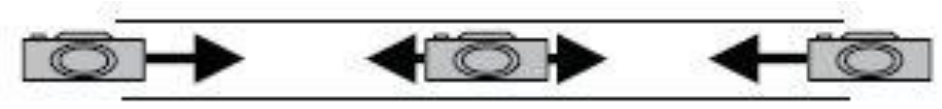

Figure 1: Photographing Location and Direction

First, two investigators evaluated each street for perceived safety, upkeep (as an indicator of physical incivilities) the extent to which they afford wide vista (prospect) and ease escape for a potential victim and concealment opportunities for potential offender, the density and height of trees, shrubs, and walls at the site by using a seven point Likert scale.

Then, 127 students, studying in the City and Regional Planning Department at Dokuz Eylul Univesity, Izmir, Turkey, evaluated 5 streets (which were randomly selected among 68 streets) via photographs. Similar to on site evaluations, students used a seven point Likert scale. Those 127 participants evaluated the streets in three groups of 35, 45 and 47 people and each street was evaluated by minimum 9 maximum 14 participants.

\section{Participants}

The average evaluations for each street showed significantly high correlations between two groups of participants: 2 participants who evaluated the streets on site and 127 participants who evaluated the streets via photographs. Thus, responses on site and responses to photographs were aggregated.

Table 1 shows the characteristics of 129 participants. More males than females were participated in the study. Majority of participants' ages ranged from 18 to 25 . More than half of the participants reported an average income between $565 \$$ to $1695 \$$ and household size as 4 or less. Less than one fourth grown up in metropolitan cities and experienced a prior victimization. About half of the participants reported that their relatives or friends experienced prior victimization.

Table 1: Participants' Demographics

\begin{tabular}{|l|l|}
\hline Gender & 51 female, 78 male \\
\hline Age & $\begin{array}{l}\text { Ranged from } 18 \text { to } 37 \text { (18 to } 25 \text { for } 126 \\
\text { participants and 33-37 for } 2 \text { participants) }\end{array}$ \\
\hline
\end{tabular}


Akman Cinar, E., \& Cubukcu, E. / Asian Journal of Environment-Behaviour Studies (ajE-Bs), 3(7) Mar / Apr 2018 (p.129-136)

\begin{tabular}{|l|l|}
\hline Income & $\begin{array}{l}0-565 \$: 32 \text { participant } \\
565-1695 \$: 74 \text { participants } \\
\text { more than } 1695 \$: 20 \text { participants }\end{array}$ \\
\hline Household Size & $\begin{array}{l}\text { Equal or Less than 4 people: } 68 \text { participants } \\
\text { More than } 4 \text { people: } 58 \text { participants }\end{array}$ \\
\hline Grown-up & Metropolitan cities : 30 people Other cities: 97 participants \\
\hline Prior Victimization (her / his- self) & $\begin{array}{l}\text { Yes: } 23 \text { (19 of whom experienced property crime) } \\
\text { No: } 106\end{array}$ \\
\hline Prior Victimization (her / his friends or relatives) & $\begin{array}{l}\text { Yes: } 62 \text { (48 of whom experienced property crime) } \\
\text { No: } 54\end{array}$ \\
\hline
\end{tabular}

\subsection{Results}

Comparing mean values of micro scale environmental characteristics in streets with zero crime and streets with at least one crime occurrence

Independent sample $t$-test analyses showed insignificant difference between streets with zero crime and streets with at least one crime occurrence on measures of prospect, escape, concealment, upkeep, and density and height of trees, shrubs and walls (Table 2).

Table 2: Independent Sample t- test Analyses on Crime

\begin{tabular}{|c|c|c|c|c|}
\hline & & No Crime & At Least One Crime & \\
\hline & prospect & $3.87(0.94)$ & $4.24(1.18)$ & $t=-1.32, d f=66, p=0.19$ \\
\hline & escape & $3.96(0.80)$ & $4.00(0.91)$ & $t=-0.63, d f=66, p=0.53$ \\
\hline & concealment & $4.23(0.52)$ & $4.17(0.70)$ & $t=0.37, d f=66, p=0.71$ \\
\hline & upkeep & $3.82(1.13)$ & $4.25(1.16)$ & $t=-1.47, d f=66, p=0.15$ \\
\hline \multirow[b]{2}{*}{$\begin{array}{l}\mathscr{W} \\
\stackrel{\Phi}{ \pm}\end{array}$} & density & $3.65(1.54)$ & $4.04(1.36)$ & $t=-1.10, d f=66, p=0.27$ \\
\hline & height & $3.93(1.22)$ & $4.17(1.09)$ & $t=-0.82, d f=66, p=0.41$ \\
\hline \multirow[b]{2}{*}{ 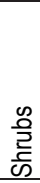 } & density & $2.42(1.00)$ & $2.75(1.18)$ & $t=-1.16, d f=66, p=0.25$ \\
\hline & height & $2.23(0.69)$ & $2.43(0.84)$ & $t=-1.01, d f=66, p=0.32$ \\
\hline \multirow[b]{2}{*}{$\frac{\infty}{\bar{N}}$} & density & $3.43(1.26)$ & $3.37(1.19)$ & $t=0.20, d f=66, p=0.84$ \\
\hline & height & $3.10(1.22)$ & $3.26(1.01)$ & $t=-0.57, d f=66, p=0.57$ \\
\hline
\end{tabular}




\section{Comparing mean Values of Micro Scale Environmental Characteristics in Streets that Feel Safe and Unsafe}

Looking at the distribution of perception of safety among 68 streets, the ones rated as 0 4.5 were coded as "safe" streets and the others rated as

4.5 to 7 were coded as "unsafe" streets. Independent sample $t$-test analyses showed significant differences between safe and unsafe streets on measures of prospect, escape, concealment, upkeep, and density and height of shrubs and walls (Table 3). Results showed that streets rated as safe provide wider field of view, ease of escape, better upkeep, less concealment opportunities, and less and lower shrubs and walls.

Table 3: Independent Sample t-test Analyses on Perception of Safety

\begin{tabular}{|c|c|c|c|c|}
\hline & & Safe & Unsafe & \\
\hline & prospect & $4.68(0.90)$ & $3.33(0.85)$ & $t=6,29, d f=66, p=0.00$ \\
\hline & escape & $4.46(0.70)$ & $3.27(0.54)$ & $t=7,62, d f=66, p=0.00$ \\
\hline & concealment & $4.05(0.61)$ & $4.39(0.63)$ & $t=-2,20, d f=66, p=0.03$ \\
\hline & upkeep & $4.74(0.89)$ & $3.21(0.86)$ & $t=7,13, d f=66, p=0.00$ \\
\hline \multirow[b]{2}{*}{$\begin{array}{l}\mathscr{W} \\
\stackrel{\Phi}{ \pm}\end{array}$} & density & $3.82(1.30)$ & $4.00(1.6)$ & $t=-0,53, d f=66, p=0.60$ \\
\hline & height & $4.26(0.91)$ & $3.84(1.36)$ & $t=1,55, d f=66, p=0.13$ \\
\hline \multirow[b]{2}{*}{ 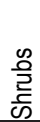 } & density & $2.31(1.00)$ & $3.06(1.14)$ & $t=-2,88, d f=66, p=0.00$ \\
\hline & height & $2.15(0.76)$ & $2.62(0.76)$ & $t=-2,54, d f=66, p=0.01$ \\
\hline \multirow[b]{2}{*}{$\frac{\omega 0}{\bar{N}}$} & density & $3.03(1.20)$ & $3.88(1.05)$ & $t=-3,07, d f=66, p=0.00$ \\
\hline & height & $2.86(1.06)$ & $3.65(0.96)$ & $t=-3,15, d f=66, p=0.00$ \\
\hline
\end{tabular}

\section{Correlation Analyses between Micro Scale Environmental Variables and Perception of Safety}

Correlation analyses were run between perception of safety and micro scale physical environmental features. Results showed significant and positive correlations between perception of safety and wider prospect $(r=0.747, p=0.000)$, ease of escape $(r=0.803, p=$ $0.000)$ and better upkeep $(r=0.801, p=0.000)$. Negative correlations were observed between perception of safety and better opportunities for concealment $(r=-0.420, p=0.000)$, higher densities of shrubs $(r=-0.507, p=0.000)$ and walls $(r=-0.465, p=0.000)$ and higher shrubs $(r=-0.452, p=0.000)$ and walls $(r=0.463, p=0.000)$. The correlation between perceptions of safety and density and height of trees were not statistically significant.

\subsection{Conclusion}

This study provides empirical evidence on the relation between 'perception of safety' (or fear of crime) and physical incivilities, prospect, refuge and closure. Lack of upkeep (or incivilities), limited prospect, affordances for concealment, blocked escape, denser and higher shrubs and walls decreases the sense of safety. However, the effect of those 
variables on crime was insignificant. Low (crime free streets) and high (at least one type of crime committed streets) crime streets were evaluated as similar in terms of physical incivilities, prospect, refuge and closure.

The results of this study have practical implications for urban design. Urban designers may control micro level physical environmental (proximate) cues to reduce fear and crime. Especially for "hot spot" areas where crime and fear is a major concern, the environmental elements could be reorganized to provide wider prospect and affordances for ease of escape and limited opportunities for concealment.

The methodological limitations of this study should be addressed to make use of conclusions with caution and to bring forth some interesting future research areas. There were five limitations related to the experimental set up and the characteristics of the subject group. First, subjective evaluations were used to measure prospect, refuge and closure. Future studies should develop more objective measures, as such measures could have more applied value for designers. Also, open ended responses were not used in this study, such measures may be more informative. Second, as the concept of crime is complex and many factors may affect it, this study tested the influence of each independent factor separately and ignored many other potential factors (especially the personal and social ones). Subsequent work may analyze composite effect of the factors of interest (such as prospect refuge and closure) and extend the variable set. Third, crime data was analyzed at street level and the streets were grouped according to crime rate. However, street lengths vary and influence the crime rate. A good extension of this study may map the precise location of crime and investigate the physical environmental features and perception of safety in those areas. Fourth, in the present study young adults rated their perception of safety for a variety of streets. Whether the results of the present study will apply to other populations (especially the disadvantageous groups children, elderly and handicapped) remains to be seen.

\section{References}

Ergun, N. \& Yirmibesoglu, F. (2007). Distribution of Crime Rates in Different Districts in Istanbul. Turkish Studies, 8, 435-455.

Maslow, A. (1943). A Theory of Human Motivation. Psychological Review, 50, 370-396.

Newman, O. (1972). Defensible Space. Crime Prevention through Urban Design. London: MacMillan.

Nasar, J.L. \& Fisher, B. (1992). Design for Vulnerability: Cues and Reactions to Fear of Crime. Sociology and Social Research, 76, 2, 48-58.

Stoks, F. G. (1983). Assessing urban public space environments for danger of violent crime especially rape. In D. Joiner, G. Brimikombe, J. Daish, J. Gray \& D. Kernohan, Eds., PAPER: Proceedings of Conference on People and Physical Environment Research, Wellington, New Zealand: Ministry of Public Works and Development, 331-342.

Appleton, J. (1975). The Experience of Landscape. London: John Wiley.

Nasar, J. L. \& Fisher, B. (1993). "Hot Spots" of Fear of Crime: A Multiple-Method Investigation. Journal of 
Akman Cinar, E., \& Cubukcu, E. / Asian Journal of Environment-Behaviour Studies (ajE-Bs), 3(7) Mar/Apr 2018 (p.129-136)

Environmental Psychology, 13, 187-206.

Nasar, J. L., Fisher, B. \& Grannis, M. (1993). Proximate physical cues to fear of crime. Landscape and Urban Planning, 26, 161-178.

Fisher, B. \& Nasar, J. L. (1992). Fear in relation to three site features: Prospect, refuge and escape. Environment and Behavior, 24, 35-62.

Fisher, B. \& Nasar, J. L. (1995). Fear spots in relation to microlevel physical cues - exploring the overlooked. Journal of Research in Crime and Delinquency, 32, 2, 214-239.

Nasar, J. L., \& Jones, K. M. (1997). Landscapes of fear and stress. Environment and Behaviour, 29(3), 291-323. 